\title{
OS AGENTES DA INSTRUÇÃO PÚBLICA
}

\author{
Flávia Obino Corrêa Werle*
}

SINTESE - Discute a instrução pública a partir de seus agentes e os processos formativos de seleção, instrução, contratação, especialização e diferenciação que ao longo do tempo constituíram o professor contribuindo para a formação do cidadão e institucionalização da educação no Rio Grande do Sul.

PALAVRAS-CHAVE - agentes sociais, instrução pública.
ABSTRACT - Discuss the public instruction having as a base its agents and the formative process of selection, instruction, contraction, specialization and differentiation that, by the evolution of time, constitute the professor contributing to the citizen formation and the institutionalization of the education in Rio Grande do Sul.

KEY WORDS - public instruction, social agents.

A elaboração de políticas públicas ${ }^{1}$ referentes à educação envolve certo nível de diferenciação institucional, especialização de agentes e geração de linguagens e saberes específicos, ou seja, de formalização do aparelho político-administrativo do Estado. Um dos espaços de formação dos indivíduos e de constituição do cidadão é a instalação da instrução pública enquanto instituição escolar obrigatória e gratuita que impõe códigos de procedimentos e currículos que veiculam saberes.

Os processos de institucionalização da instrução pública incorporam e reconhecem práticas e atividades em vigor apoiadas pela tradição, as reelaboram, modificam, reapresentam de forma mais complexa. Assim a ação da família e de comissões de cidadãos foi sendo reelaborada, substituida pela escola formal e um corpo de agentes ${ }^{2}$ foi se formando, profissionalizando progressivamente com a estruturação, diferenciação e especialização da instrução pública.

Os agentes do sistema político-administrativo da educação atuam no processo de imposição e conformação do cidadão sendo também por ele configurados. Sua ação se efetua desde os ministérios, secretarias, departamentos, setores, unidades

* Professora titular na Universidade do Vale do Rio dos Sinos (UNISINOS) e PUCRS. Doutora em Educação.

1 Embora sendo um termo de dificil definição, as políticas públicas são aqui referidas às formas variadas que na prática se expressam na legislação, em recomendações e relatórios oficiais.

2 Agentes do sistema político administrativo da educação incluem os professores e demais funcionários do aparelho educativo tais como diretores, supervisores, inspetores, coordenadores. A diferenciação referida aos agentes eduçativos vai desde a fase das práticas de perceptorado (ação individual realizada junto à célula familiar) ao professor assalariado, com direitos e deveres assentados em um contrato de trabalho. 
de ensino, salas de aula e demais componentes institucionais materializando as diretrizes de formação do cidadão. Os agentes educativos são a um só tempo responsáveis pela institucionalização da instrução pública e por ela formađos em sua estrutura material, curricular e de gestão para serem formadores de cidadãos, desenvolvendo e reapresentando saberes e práticas de urbanidade e cidadania.

$\mathrm{Na}$ medida em que o sistema educativo foi se estruturando, um conjunto de características referentes ao seu funcionamento e identidade foram se manifestando. Unificação, sistematização, diferenciação e especialização, bem como substituição, expressam processos estruturadores da ação educativa, decorrentes e exigidos pela concentração cada vez mais densa da população nas cidades. É a estruturação do sistema político-administrativo da educação que assegura a este sistema possibilidade e legitimidade no manejo e transmissão da urbanidade (comportamentos pautados por cortesia, afabilidade, contratualidade, precisão, pontualidade, interdependência e higiene) civilizando e polindo as relações, as pessoas e os espaços da cidade.

A ação educativa da instância estadual privilegiou e privilegia o espaço urbano. Não apenas a criação da escola pública está atrelada à urbe mas a sua diferenciação e classificação. As cidades exercem função de centros político-administrativos na estruturação da instrução pública, organizando relações que ocorrem na área urbana, diferenciando-as das de áreas rurais. Os processos de estruturação da instrução pública ocorrem por diferenciação e contraposição com os de zonas rurais, distanciando e qualificando as cidades frente a outros espaços.

Apesar da incipiente urbanização no período em estudo, havia um diferencial de pagamento de professores conforme as classes se localizassem em centros mais ou menos populosos - freguesias, vilas ou cidades - o que também definia o contrato que mantinham, o gênero dos contratados, o currículo, a profundidade no tratamento dos conteúdos de ensino e os saberes exigidos dos professores. As aulas das cidades eram um espaço de instrução pública mais qualificado do que 0 das vilas e freguesias o que também qualificava os que nela trabalhavam e os que as freqüentavam. A obrigatoriedade impondo a instrução primária em freguesias e povoações estava delimitada ao perímetro de um quilômetro medido da sede da escola. Era a estruturação da instrução pública e sua oferta associadas aos processos de urbanização da época.

No caso da instrução pública elementar a localização das escolas e o tipo de espaço físico que se constituíram no período foram formando os agentes do Estado, pela produção de categorias e distinções marcadas por questões relacionadas a gênero, capital cultural e remuneração diferencial de serviços. Era uma diferenciação que resultava de saberes incorporados pelas estruturas de instrução pública necessários para justificá-las e legitimá-las junto à população. Estes saberes que se materializavam em estruturas institucionais diferenciadoras eram importados de outros países (em geral França, Inglaterra e Estados Unidos; as obras de Hippeau ${ }^{3}$

3 HIPPEAU, M. C. A instrução pública nos Esstados Unidos: escolas públicas, colégios, universidades, escolas especiais. Relatório dirigido ao Ministro de Instrução Pública em França. Rio de Janeiro: Typographia Nacional, 1871. HIPPEAU, C. A instrução pública na Inglaterra. Rio de Janeiro: Typographia Nacional, 1874. 
para isso muito contribuiram) e, pela força de sua cientificidade, civilidade e inovação, ${ }^{4}$ se colocavam como importantes formadores de estruturas e de modelos de cidadania a serem imitados.

A base material, intimamente ligada à diferenciação da base de gestão, produzia-se na instrução pública da Província de São Pedro do Rio Grande do Sul em decorrência de suas relações com a estrutura institucional do campo educativo tanto no âmbito do poder central como no internacional.

A insipiência das estruturas de gestão fazia com que os limites entre público e privado fossem pouco claros. As estruturas de controle e inspeção do trabalho docente foram se constituindo pouco a pouco e em decorrência do desenvolvimento do suporte financeiro e administrativo-institucional do campo do poder. Participar dos colegiados, ${ }^{5}$ que eram verdadeiras estruturas de controle do aparelho institucional da instrução pública, era manifestação de cidadania e símbolo de desprendimento e serviço público, que colocava a quem o fizesse mais no campo do poder do que atestava seu conhecimento técnico científico referido ao campo educacional. A ação destes colegiados formava o ser professor pelas recomendações, pareceres e punições de que dispunham e era um exemplo concreto do fazer-se cidadão produzindo relações sociais amplamente modeladoras da urbanidade e da cidadania. Os colegiados locais caracterizavam-se como organismos executivos, com funções de controle e inspeção e não normativos. Seus membros não eram escolhidos com base na competência técnica ou devido a posse de título ou diploma, mas com base no compromisso político, decorrência da fraca especialização das estruturas institucionais, da gratuidade com que tal serviço era prestado e da não-exigência de domínio de saberes técnicos especificos para a função. Este critério de seleção era legitimo o suficiente para atribuir autoridade ao cidadão escolhido que aplicava normas e códigos controlando professores e alunos e atuando por mandato da Diretoria de Instrução Pública da Provincia.

A obrigatoriedade escolar na Província de São Pedro do Rio Grande do Sul, definida em 1871, trouxe para a Diretoria de Instrução Pública questōes referentes à seleção, formação e designação de pessoal para as escolas, embora a liberdade de ensino apontasse em direção à desregulamentação do exercício do magistério.

Como na época as escolas elementares eram mais freqüentadas por meninos do que por meninas e, como os processos de formação eram diferenciados por gênero, meninos e meninas estudavam em escolas separadas, não havia como, em decorrência da baixa remuneração, manter apenas professores homens em aulas de instrução elementar para meninos. A freqüência de mulheres à Escola Normal

4 Os textos "A cidade como fator de diferenciação da rede escolar: do período imperial à primeira república" (História da Educação - ASPHE, FaE/UFPel, v.1, n. 1, p. 91-97, abr. 1997), "Educação riograndense no inicio do período republicano: do apoio ao privado à sua publicização" (Educaçăo e Sociedade, ano 17, n. 54, p. 70-89, jan. 1996) e "Instrução pública e processos de disciplinamento da infância" (mímeo) produzidos no contexto deste subprojeto detalham e exemplificam estas noções.

5 Ver o texto "Conselhos Municipais de Educação: estudo genético histórico" (Cadernos de Pesquisa, n. 103, p. 123-135, mar. 1998). 
Primária (criada no Rio Grande do Sul em 1871 e de efêmera duração), demonstrava e justificava que $o$ atendimento a classes elementares masculinas fosse também feito por professoras. Professoras formadas na Escola Normal, se "escrupulosamente selecionadas", poderiam participar do "ensaio" da nova prática: mulheres exercendo o magistério em classes elementares masculinas.

Havia forte articulação do paradigma masculino aos processos formativos, métodos de ensino e ao tipos de escola. No início da escolarização e experimentalmente era aceito que mulheres ensinassem aos meninos, não em niveis mais adiantados. Era necessário convencer a população que as características femininas de amor e brandura eram também úteis ao ensino elementar junto aos meninos.

A palmatória, severidade e autoritarismo eram entendidos como processos formativos próprios para meninos e legitimamente praticados por professores homens. Os professores particulares homens poderiam submeter-se a concurso para as cadeiras públicas que estivessem vagas sem a necessidade de uma habilitação oficial obtida na Escola Normal. Esta entretanto era exigida para as mulheres. Em espaços não urbanos as aulas mistas eram melhor aceitas do que em vilas e cidades onde preferencialmente meninos e meninas recebiam formação em ambiente e currículos diferenciados.

Os concursos, feitos por examinadores que não eram portadores de título específico de formação profissional, foram, por longo tempo, uma estratégia de controle de qualidade e de confirmação da capacidade profissional dos professores públicos. A moralidade era um importante quesito de seleção assim como maioridade legal que, para as mulheres solteiras, era a idade de vinte e cinco anos. A capacidade profissional era verificada por exames orais e escritos referentes a conteúdos de ensino elementar. A criação da Escola Normal (1871) no Rio Grande do Sul foi um passo na institucionalização e formalização da habilitação para o magistério público. Cercava-se de benefícios diferenciadores, assegurando a seus egressos nomeação imediata, dispensa de exames, vencimentos mais altos e vitaliciedade no magistério.

A Escola Normal Primária prometia ser uma alternativa de formação de professores de instrução pública em substituição aos exames e concursos. Isto na prática não se confirmou. Os processos de formação de professores estruturados como cursos se institucionalizaram com a Escola Complementar que funcionou no Rio Grande do Sul até 1946. Em 1943, eram 25 as instituições que mantinham curso complementar de formação de professores, dentre as quais predominavam as particulares equiparadas.

A escola elementar de instrução pública era a base institucional do conhecer, do fazer e do ser professor. Era ao mesmo tempo base institucional, formativa e de produção de saberes profissionais dos agentes do Estado e importante espaço de formação da população e sua civilização e conformação aos valores e práticas urbanas.

Havia uma intima interação entre as características de especialização e diferenciação da base material da instrução pública com a produção do curriculo e remuneração dos professores. As entrâncias, graus e tipos de escolas não eram 
estruturas provenientes de uma certa localização mas também de uma diferenciação dos processos de gestão e dos saberes envolvidos no currículo escolar e nas práticas docentes.

As bases material e de gestão decorrentes da institucionalização da instrução pública produziam pedagogias específicas junto aos agentes do Estado e ao cidadão. Eram pedagogias que levavam uma forte marca diferenciadora de gênero ${ }^{6} \mathrm{o}$ que contribuía para configurar o campo educativo e marcar a posição do mesmo frente aos demais.

6 Sobre gênero ver os textos "Feminização do magistério como estratégia...", "A cidade como fator de diferenciação...", "Instrução pública e processos de disciplinamento..." 